\title{
Risk of suicide in neurological wards: Assessment and interventions
}

\author{
Petra Ott-Ordelheide ${ }^{1}$, Rüdiger Noelle ${ }^{2}$ \\ 1. Evangelisches Krankenhaus Bielefeld, Krankenhaus Mara, Bielefeld, Germany. 2. Fachhochschule der Diakonie Bielefeld, \\ Germany
}

Correspondence: Petra Ott-Ordelheide. Address: Maraweg 17, 33617 Bielefeld, Germany.

Email: Petra.Ott-Ordelheide@mara.de.

Received: May 13, 2013

Accepted: June 19, 2013

Online Published: April 21, 2014

DOI : $10.5430 /$ jnep.v4n7p41

URL: http://dx.doi.org/10.5430/jnep.v4n7p41

\begin{abstract}
Nurses in every ward of hospitals have contact to persons who are at risk of suicide. The article focuses on patients in neurologic wards. Based on an analysis of relevant literature and evaluation of biographies of patients importance will be demonstrated. There after follows a definition of significant terms and their integration into the practical nursing process.

Result: The identification of patients with risk of suicide might be difficult, but the perception of transference and countertransference includes the possibility for nurses and patients to find out the right way of communication, interventions and security.

Nurses in every ward of hospitals have contact to persons who are at risk of suicide.

Nurses often remember patients with this risk, because they often need special interventions. Emotional aspects are very important for nurses and patients, when they have suicide thoughts during their stay in hospital.

In some cases patients need time for convalescence of multiple sclerosis or in case of a stroke, they need diagnostic intervention.

Patients with neurological problems are more often than other groups of patients confronted with years of risk of suicide. The following article focuses on this group of people and the possibilities of nurses to assess, to intervene and to evaluate.

In the past years Nursing science developed a variety of methods interventions, measuring instruments and guidelines for patients at risk of suicide in psychiatric hospitals. For staff in psychiatric hospitals the management often implements support for nurses who are confronted with suicide and risk of suicide. The article discusses these methods and support for patients with neurological problems and nursing staff on neurology wards.
\end{abstract}

\section{Key words}

Risk of suicide, Neurological patients, Nursing process, Nursing interventions

\section{Introduction}

Nurses in every ward of hospitals have contact to persons who are at risk of suicide. The article focuses on patients in neurologic wards. Based on an analysis of relevant literature and evaluation of biographies of patients importance will be demonstrated. There after follows a definition of significant terms and their integration into the practical nursing process. 


\section{Case study}

Mrs. $\mathrm{L}$ is a 45 year old woman. She lives in a little town in northern Germany. She works in an office. She suffered from epilepsy since she has been 14 years old. As a young adolescent she took her medicine and has not got any problems to cope with her epilepsy. Five years later it was difficult for her to find a partner and to contact other people. Most of her life she was single, because lots of men, could not accept the epilepsy. At the age of 35 she suffered a relapse of seizures. She was given several medicine trials, and afterwards stayed in hospital for diagnostic of surgical treatment of her epilepsy. The result of diagnostic was that there is no surgical, because she has a bitemporal lobe epilepsy. While talking about the results with doctors and nurses, she seemed to be fine and she agreed to go to another ward, the opportunity to test better medicines. In the morning of discharge a nurse found her in bed without any reaction, deep asleep. Several times the nurse tried to wake her up without success. The nurse called her colleague and together they tried to find out why the patient had problems to react. At first the physician thought, there was an ictal event and wanted to do an EEG, but the nurse found two empty packages of medicine in the patient's night cabinet. Immediately a stomach flushing was arranged and Mrs. L survived. After readjustment of antiepileptic drugs, she was free of seizures for one year and went to an ambulant psychiatric center to cope with her mental and psychiatric problems.

\section{Risk of suicide}

Risk of suicide is a description for all behaviors and thoughts of humans, who have an auto destructive character and their intention is to die ${ }^{[1]}$.

\section{Basic risk of suicide}

This term describes patients at a latent risk of suicide, they often have some risk factors, sometimes they speak about their thoughts, they attempted to suicide in the past. Senses of nurses are equal to behavior and expressions of patients ${ }^{[1]}$.

\section{Acute risk of suicide}

If patients have an acute risk of suicide, they speak about concrete plans to do, or change their behavior in an expectable way. They can't distance themselves from their thoughts of suicide, they can be hopeless, they don't have a perspective for future, they are isolated, they are aggressive, agitated or depressive ${ }^{[1]}$.

\section{Risk of suicide}

Illness of mind is an important aspect for risk of suicide. Depressions are the most important variable. In Germany there more people die of suicide than in traffic accidents ${ }^{[2]}$. In the group of young adults suicide is the most common cause of death. There is the group of young adults with high risk of parasuicide. Patients with schizophrenic psychosis are the greatest group who done suicide in hospitals ${ }^{[2]}$.

\section{Risk factors for suicide:}

Patients, who

(1) are single

(2) who often have depressive feelings

(3) have interpersonal conflicts

(4) have feelings of aggression, hopelessness, helplessness

(5) have problems on their job

(6) who are addicted to alcohol and drugs 
(7) have someone in their family, who committed suicide or parasuicide

(8) who have a broken home situation

(9) and have psychiatric morbidity ${ }^{[1]}$

Bell et al. shows that patients with epilepsy especially if they are newly diagnosed have a greater risk of suicide.

If they have a temporal lobe epilepsy or if they are after surgery of temporal lobe epilepsy and if they are in an institution or in a clinic for tertiary care they have an extra risk of suicide. The risk of suicide is low in with groups of patients who suffer from epilepsy as well as learning disabilities. A study in Brazil shows the risk of suicide and suicide thoughts: Patients with epilepsy have more thoughts of suicide (36.7\% Patients with epilepsy vs. $23.8 \%$ patients without epilepsy) ${ }^{[3]}$.

A case control study in Sweden shows a multiple increase of risk of suicide for patients with epilepsy and mental illness and $10 \mathrm{fold}$ risk of suicide for patients with epilepsy and antipsychotic drugs. Early onset in the adolescence might be a risk factor, too ${ }^{[4]}$.

Gender has no effect on the rate of suicide of patients with epilepsy, but the group of patients with epilepsy itself is at higher risk of suicide ${ }^{[5]}$.

Also patients with a stroke are at double risk suicide ${ }^{[6]}$. Predictors are the age, duration of stays at hospital and diagnosis ${ }^{[7]}$. A Danish study shows that $7.2 \%$ of all the suicides that were done in the area of Funen, Denmark, are related to the diagnosis stroke. The rate of mortality is mainly due to mainly to cardiovascular diseases followed by cancer, accidents and suicide ${ }^{[8]}$.

\section{The attitude of nurses}

For nurses it is important to think about their own emotions and attitudes to suicide and patients at risk of suicide. One central aspect is recovery for this group of patients. Risk factors in behavior of nurses are:

(1) If nurses are discouraged, when they think about the situation of the patient

(2) if nurses are not sure, how they can react to risk of suicide

(3) if nurses criticize patients with suicide thoughts

(4) if nurses have high expectations of patients

(5) if nurses can't mediate that there are different therapeutic possibilities to help

(6) covered transference and countertransference from patients' emotions to nurses ${ }^{[2]}$

\section{Risk factors of suicide in hospitals}

Patients with risk of suicide are very sensitively of situations of change: a new therapist starts, the plan of discharge, or another patient commits suicide. Also new concepts of therapeutic teams, wards without structure, change of the group of patients, mistakes of diagnostic and therapy, and pressure of rehabilitation. These aspects are hypothesis and needs scientific evidence ${ }^{[2]}$. 


\section{Guidelines}

There are several national and transnational guidelines ${ }^{[9-11]}$ for patients at risk of suicide, often combined with guidelines for nursing treatment of depression.

In many European states depression is ranked No. 5 of the top diseases ${ }^{[9]}$. Horatio defined the role of nurses in preventing suicide: Based on WHO a report on monitoring and evaluation of mental health, one of the strategies is to enrich the mental health expertise of general health workers. In Europe about 6.5 million nurses (WHO) ${ }^{[10]}$ confronted with depressive patients and terms of self harming or suicidal behavior. Repper et al (1999) ${ }^{[9]}$ describes that general health workers and patients benefit, if specialized psychiatric nurses are available in departments of Emergency and Accident.

In New Zealand exists a best practice guideline.

They identify key messages:

(1) Anyone who talks about suicide is taken seriously

(2) Asking about suicide does not create risk of suicide

(3) Case notes should be supported by assessments

(4) Nurses should involve family/ support people whenever possible

(5) cultural characteristics should be taken into consideration

(6) a safe environment should be provided for people who are intoxicated (New Zealand Guideline Group)

\section{Transcultural aspects}

For nurses it is important to know that different ethnic groups are at risk of suicide to a different. But the contemplation of ethnic groups must be done carefully, because there are great differences within a group and within a country.

For example in Sri Lanka in Asia there exists districts with a rate of suicide of 112.2 per 1000 deaths in Vanvuniya and with 10,8 deaths per 1000 deaths in others places like for example Colombo ${ }^{[13]}$.

In Western Europe the rate of suicide attempts differs in different places.

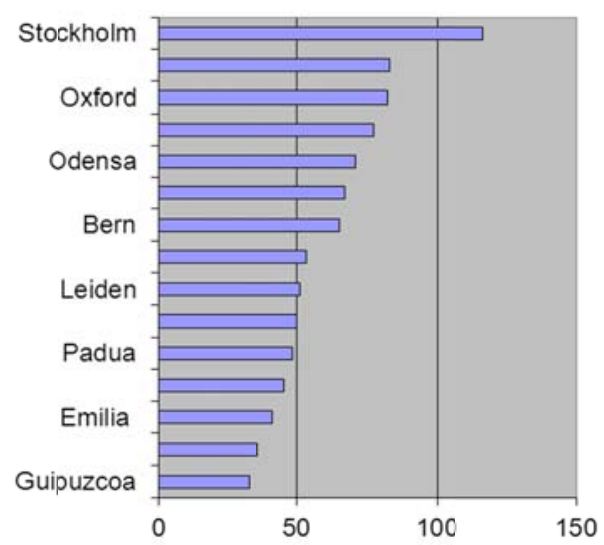

Figure 1. Rate of suicide attempts/ per 100.000 inhabitants/ over 65 years ${ }^{[14]}$ 
This rate refers to elderly people over 65 years. The group of the elderly was chosen, because the probability of neurological problems decreases over 65.

\section{Socio cultural aspects}

Socio-cultural aspects can be risk- factors for suicide:

(1) Stigma associated with help- seeking behavior

(2) Barriers to assessing health care service, especially health care service

(3) Certain religious and cultural beliefs, for example the idea that suicide is a method to solve a personal dilemma

(4) Exposure to suicide behaviors (personal or media) ${ }^{[10]}$

\section{Nursing process}

For nurses it is important to find out which patients are at risk of suicide. The finding is a key for all following interventions.

Patients and nurses often communicate about neurological aspects and do not focus on emotional problems. The first assessment focuses on neurological topics like symptoms of a stroke, frequencies of seizures, or side- effects of medicines against multiple sclerosis. It is also important to do a risk- assessment. Risk of suicide has to be one part of this assessment.

Especially the assessment of elderly people with neurological diseases is very important.

But it is more difficult for nurses to ask the patient about their risk of suicide. Patients sometimes are unsettled by a psychiatric assessment.

The following questions can be a start to talk about risk of suicide:

\section{Example 1}

(Assessment.....)

Nurse: Patients with epilepsy (...) sometimes have emotional problems...

Patient: What do you mean?

Nurse: There are some, who have phases of sadness or euphoric feelings.

Patient: Yes sometimes I'm very sad about my life with epilepsy, I don't have the same options like others have.

Nurse: Some people who have problems with sadness, sometimes think about suicide, do you actually think about it or thought about it in the past?

\section{Example 2}

When the patient stays in the department some days and nurses have the impression, that the patient is withdrawn, the nurse can talk to him. 
Nurse: I have the impression that you think about something intensively...

Patient: That's right.

Nurse: Can you describe to me, what you are thinking about?

Patient: Yes well, I am in a very difficult situation...

Nurse: Please let us talk about it might be difficult for you to cope with certain emotional aspects....

Sometimes it is useful to do a special assessment. If nurses identify a risk of suicide, it is unlikely that staff members of neurological departments have deeper knowledge. Nurses have to think profoundly about the goal of the nursing process: If there is no psychological support for patients, nurses can't expect that the risk of suicide or suicide thoughts sinks.

\section{Questions:}

If nurses identify a person at risk of suicide, following questions can be useful:

Have you recently thought about suicide in the last time?

Do you have concrete ideas how to do suicide?

Do you prepare your plan of suicide?

Did you speak about your plan to someone?

Have you done suicide in the past?

Has someone in your family or friends do suicide?

Do you think your situation is hopeless?

Is it difficult for you to think about something else than your problems?

Do you have less contact to your family and friends?

Do you have someone, you can talk?

Do you live together with someone?

Do you feel obliged to someone of your friends or family?

Are you a member of a religious or spiritual community ${ }^{[1]}$ ?

All assessments and examples can identify patients with a risk of suicide, but it is also important for nurses to find interventions. Patients with neurological problems need certain interventions. Nurses have to think about possible interventions are.

\section{I nterventions}

Lots of interventions for patients at a risk of suicide are possible:

The intervention with the highest priority is to be in contact with the patient, and to build up a good relation.

If patients have an acute risk of suicide a special therapeutic and psychiatric setting is useful. If patients are at a basic risk of suicide, they should have a double room and take part in activities of the hospital or department. The danger of suicide should assessed and documented for all members of the therapeutic team: physicians, working therapy, relations etc. 
Sometimes it seems easier, to talk with patients about a flyer. The experience is, it is easier for patients to talk about patients with epilepsy or stroke in general, than the once own personal situation of someone. A flyer about emotional problems might be a good help.

\section{I nterventions of security}

Departments should evaluate, if there are possibilities to commit suicide very easily, for example: open windows on higher floors. Other interventions for security are not useful in a neurological department and can be done in psychiatric specialized care units: for example to take out glass etc. Quality of life and interventions of security should be in due proportion. Nurses have to decide individually for every patient at risk of suicide, how much security someone needs. Sometimes it is important to take out razor- blades, in another case the priority should be that nurses look after someone profoundly.

\section{Structure of daily life}

A certain structure of the daily life of a patient helps to concentrate on other things like thoughts of suicide.

\section{Discussion}

Risk of suicide is one underestimated risk of patients in neurological departments.

The first step for nurses is the most difficult step: to identify patients with a risk of suicide. If nurses identify a patient, different interventions are possible. The nursing process conducts nurses to helpful and useful interventions.

Perception of transference and countertransference are extreme important. Nurses should discuss and deliberate behavior and expressions of patients with risk of suicide carefully.

For nurses it is important to see the emotional aspects of neurology illness and to give patients information about possibilities, where they can get help. Especially the group of older patients should be accompanied very careful, because the rate of suicide is very high in this group. There should be more nursing science activity for elderly people at risk of suicide.

The identification of patients with risk of suicide could be difficult, but the perception of transference and countertransference include the possibility for nurses and patients to find out the right way of communications, interventions and security.

\section{References}

[1] Sauter, D., Abderhalden, C., Needham, I., Wolff, S. 2004. Lehrbuch Psychiatrische Pflege. Huber Verlag: Bern.

[2] Rahn, E., Mahnkopf, A. 1999. Lehrbuch Psychiatrie für Studium und Beruf. Psychiatrie- Verlag: Bonn.

[3] Stefanello, S. et al. Psychiatric comorbidity and suicidal behavior in epilepsy: a community based cased control study. Epilepsia. 2009; 51 (7): 1120-1125. PMid:19889019 http://dx.doi.org/10.1111/j.1528-1167.2009.02386.x

[4] Nilsson, L. et al. Risk factors for suicide in Epilepsy: a case control study. Epilepsia. 2002; 43(6): 644-651. PMid:12060025 http://dx.doi.org/10.1046/j.1528-1157.2002.40001.x

[5] Kalinin, V., Polyanski, D. Gender and suicidality prediction in epilepsy. Epilepsy and behavior. 2005; 7: 657- 663. PMid:16198152 http://dx.doi.org/10.1016/j.yebeh.2005.06.007

[6] Stenager, E, Madsen, C., Stenager, E., Boldsen, M. 1998. Suicide in Patients with stroke: Epidemiological study. British Medical.

[7] Teasdale, T., Engberg, A. Suicide after stroke: a population study. Journal of Epidemiology Community Health. 2001; 55: 863-866. PMid:11707478 http://dx.doi.org/10.1136/jech.55.12.863

[8] Bronnum- Hansen, H. et al. Long- Term- Survival and Causes of Death After Stroke. Stroke. 2001; 32: 2131 - 2136. 
[9] Van de Sande, R., Ward, M. Horatio response to suicide and depression prevention EU mental health pact progress. Available from: www.horatio.eu 15.11.2012

[10] WHO (2012) Public health action in preventing suicide. A framework. www.who.int Download 12.12.2012. Teasdale, T.; Engberg, A. Suicide after stroke: a population study. Journal of Epidemiology Community Health. 2001; 55: 863-866.

[11] Repper, L., et al. A review of literature on the prevention of suicide through interventions in Accident and Emergency departments. Journal of clinical Nursing. 1999; 8: 3-12. PMid:10214164 http://dx.doi.org/10.1046/j.1365-2702.1999.00218.x

[12] New Zealand Guideline Group (NZGG). The assessment and management of people at risk of suicide. For Emergency Departments and Mental Health Service Acute Assessing Settings. Download: 15.11.2003

[13] Kearney, R., Miller, B. The spiral of suicide and social change in Sri Lanka. Journal of Asian Studies. 1985; 45(Suppl. 1): 81-101. PMid:11617267 http://dx.doi.org/10.2307/2056825

[14] De Leo et al. Attempted and completed suicide in older subjects: results from WHO/ Euro Multicentre study of suicidal behaviour. International Journal of Geriatric Psychiatry. 2001; 16: 300-310. PMid:11288165 http://dx.doi.org/10.1002/gps.337 